Amgen, Bristol-Myers Squibb, Eli Lilly and Company, Genentech, GlaxoSmithKline, Pfizer, Regeneron and Sanofi, W. Rigby Consultant for: Roche/Genentech, N. Singer Grant/research support from: Merck/EMD Serono (in kind lab resources) and unrestricted educational grants from several companies to MetroHealth for 2016 Cleveland Society of Rheumatology, C. Birchwood Employee of: Genentech, Inc., D. Gill Employee of: Genentech, Inc., W. Reiss Employee of: Genentech, Inc., J. Pei Employee of: Genentech, Inc., M. Michalska Employee of: Genentech, Inc.

DOI: 10.1136/annrheumdis-2018-eular.1741

\section{SAT0169 NO EVIDENCE THAT CONCOMITANT GLUCOCORTICOID THERAPY AFFECTS EFFICACY AND SAFETY OF TOCILIZUMAB MONOTHERAPY IN RHEUMATOID ARTHRITIS CLINICAL TRIALS}

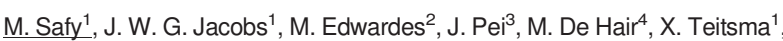
P. Welsing ${ }^{1}$, M. Borm ${ }^{5}$, Y. Luder ${ }^{6}$, J. Van Laar ${ }^{1}$, A. Pethö-Schramm ${ }^{6}$, J. W. J. Bijlsma ${ }^{1}{ }^{1}$ Rheumatology and Clinical Immunology, University Medical Center Utrecht, Utrecht, Netherlands, ${ }^{2}$ Everest Clinical Research, Markham, Canada, ${ }^{3}$ Genentech, San Francisco, United States, ${ }^{4}$ University Medical Center Utrecht, Utrecht, ${ }^{5}$ Roche, Woerden, Netherlands, ${ }^{6}$ Roche, Basel, Switzerland

Background: For rheumatoid arthritis (RA) patients included in clinical trials, background treatment with glucocorticoids (GCs) is quite common (40-60\%), but their potential contribution to efficacy and safety of the disease modifying antirheumatic drug (DMARD) tested in that trial has rarely been evaluated.

Objectives: To establish whether a stable GC dose at baseline and during the study contributed to the efficacy and safety of TCZ monotherapy initiated in RA patients in 4 TCZ RCTs. In addition, to investigate the same issue in the comparator arms of these trials, in which adalimumab (ADA) or methotrexate (MTX) was initiated.

Methods: Data from 4 randomized controlled double-blind trials (AMBITION, ACT-RAY, ADACTA and FUNCTION) with TCZ monotherapy arms was analysed in this post hoc analysis [1-4]. Study participants were MTX-naïve, intolerant or had an inadequate response to conventional synthetic DMARDs (csDMARD-IR). Because of differences between the studies in region, and baseline RA duration and disease severity, analyses were done separately for each study. Stable GC dose at baseline was allowed and was to be continued unchanged during the first 24 weeks. Analyses of covariance (ANCOVA) of change from baseline to Week 24 in CDAI and DAS28 and logistic regression analyses at Week 24 for CDAI remission and ACR50 were performed. Repeated measures analyses using all visits up to week 24 were also done. Incidence rates of serious adverse events (SAEs) were assessed by GC use.

Table 1 Disease Activities at week 24 of GC Users versus non-GC Users per Treatment per Study

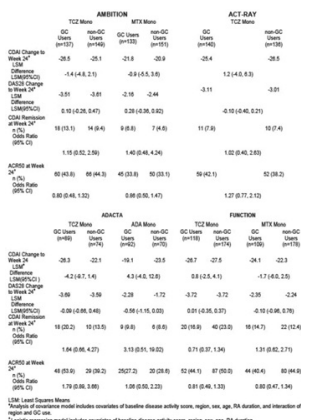

Results: Baseline characteristics were mostly comparable between GC users and non-GC users in each treatment arm for each study. The adjusted differences (95\% Cls) of CDAl change at week 24 between GC and non-GC users in TCZ arms of AMBITION, FUNCTION, ACT-RAY and ADACTA were -1.4 (-4.8, 2.1), $0.8(-2.5,4.1), 1.2(-4.0,6.3)$ and $-4.2(-9.7,1.4)$, respectively (table 1). CDAI remission rates, ACR50 response rates and DAS28 score changes at 24 weeks neither were significantly different between GC users and non-GC users in the TCZ arms, nor in the MTX and ADA arms (table 1). Repeated measures analyses to week 24 showed no significant differences in DAS28 or CDAI. Statistically significant predictors for the various clinical outcomes included baseline CDAI, baseline DAS28, age, sex, RA duration and region. A numerically higher but not significantly different SAE rate was seen in the GC-arms of all four trials, compared to the non-GC-arms.

Conclusions: No evidence was found that GC treatment at baseline and continued at a stable dose affects either clinical efficacy or safety over 24 weeks of TCZ, MTX, or ADA monotherapy initiated at baseline in RA clinical trials.

\section{REFERENCES}

[1] Jones G, et al. Ann Rheum Dis 2010;69:88-96.

[2] Dougados M, et al. Ann Rheum Dis 2013;72:43-50.

[3] Gabay C, et al. Lancet 2013;381:1541-50

[4] Burmester GR, et al. Ann Rheum Dis 2017;76:1279-84.

Disclosure of Interest: M. Safy Grant/research support from: Research grant from AZ, J. Jacobs: None declared, M. Edwardes Employee of: Everest Clinical Research, Canada, J. Pei Employee of: US Medical Affairs, Immunology, Genentech, Inc., M. De Hair: None declared, X. Teitsma: None declared, P. Welsing: None declared, M. Borm Employee of: employee of Roche Nederland BV., Y. Luder Employee of: 4 F Hoffmann-La Roche, Basel, Switzerland, J. Van Laar Consultant for: Arthrogen, MSD, Pfizer, Eli Lilly, and BMS and research grants from Astra Zeneca, Roche-Genentech., A. Pethö-Schramm Employee of: F Hoffmann-La Roche, J. Bijlsma Consultant for: Grants and fees from Roche, AbbVie, Bristol-Myers Squibb, Merck Sharp \& Dohme, Pfizer, and UCB

DOI: 10.1136/annrheumdis-2018-eular.6327

\section{SAT0170 ANTI-IL-6 THERAPY MODULATES LEPTIN IN PATIENTS WITH RHEUMATOID ARTHRITIS}

R. López-Mejías ${ }^{1}$, F. Genre ${ }^{1}$, S. Remuzgo-Martínez ${ }^{1}$, V. Mijares ${ }^{1}$, J. Calvo-Alen ${ }^{2}$ R. Blanco ${ }^{1}$, J. Llorca ${ }^{3}$, S. Castañeda ${ }^{4}$, M. A. González-Gay ${ }^{1,5,6}$. ${ }^{1}$ Epidemiology, Genetics and Atherosclerosis Research Group on Systemic Inflammatory Diseases, Rheumatology Division, Hospital Universitario Marqués de Valdecilla, IDIVAL, Santander, ${ }^{2}$ Rheumatology Department, Hospital Universitario Araba, Vitoria, ${ }^{3}$ Epidemiology and Computational Biology Department, School of Medicine, University of Cantabria, and CIBER Epidemiología y Salud Pública (CIBERESP), IDIVAL, Santander, ${ }^{4}$ Rheumatology Department, Hospital Universitario La Princesa, IIS-IPrincesa, Madrid, ${ }^{5}$ School of Medicine, University of Cantabria, Santander, Spain, ${ }^{6}$ Cardiovascular Pathophysiology and Genomics Research Unit, School of Physiology, Faculty of Health Sciences, University of the Witwatersrand, Johannesburg, South Africa

Background: Leptin is an adipocytokine that plays an important role in the regulation of body weight and also participates both in immune homeostasis and inflammatory processes $[1,2]$. Chronic systemic inflammation is of major importance in the development of atherosclerosis in rheumatoid arthritis (RA) [3]. IL-6 blocker yields a rapid improvement of endothelial function [4]

Objectives: To determine whether the infusion of IL-6 blockade improves the endothelial function by altering circulating Leptin concentrations in patients with RA.

Methods: 50 Spanish patients on treatment with anti-IL-6 monoclonal antibodyTocilizumab who fulfilled the 2010 classification criteria for RA [5] were recruited. Patients with diabetes mellitus or plasma glucose $>110 \mathrm{mg} / \mathrm{dl}$ were excluded. Leptin serum levels were determined immediately prior to (time 0 ) and after (time 60 minutes) Tocilizumab infusion by Enzyme-Linked ImmunoSorbent Assay (ELISA).

Results: A significant reduction in Leptin concentration was observed following Tocilizumab infusion (mean \pm standard deviation (SD): $9.24 \pm 7.98 \mathrm{ng} / \mathrm{ml}$ versus $7.91 \pm 7.36 \mathrm{ng} / \mathrm{ml}, \mathrm{p}<0.0011$ ). In addition, a significant positive correlation between Leptin concentration and insulin resistance (HOMA at the time of the study) was found $(r=0.40 ; p=0.0046)$. Furthermore, a significant negative correlation between Leptin levels and insulin sensitivity (QUICKI) was disclosed $(r=-0.46$; $\mathrm{p}=0.0009$ ).

Conclusions: Our study confirms that circulating Leptin concentrations are modulated by anti-IL-6 treatment. In addition, Leptin concentration correlates with insulin resistance and sensitivity. The beneficial effect of anti-IL- 6 blockage on cardiovascular mortality in RA may be mediated by reduction in serum levels of leptin.

\section{REFERENCES:}

1] Nat Rev Immunol 2006;6:772-83.

2] Nat Rev Immunol 2006;6:772-83.

3] Autoimmun Rev 2016;15:1013-30.

4] Atherosclerosis $2011 ; 219: 734-6$.

5] Arthritis Rheum 2010;62:2569-81.

Acknowledgements: This study was supported by European Union FEDER funds and "Fondo de Investigación Sanitaria" (Pl15/00525) from "Instituto de Salud Carlos III' (ISCIII, Health Ministry, Spain). It was also partially supported by RETICS Program RD16/0012 (RIER) from the ISCIII, and in part by grants from the European IMI BTCure Program. RL-M is a recipient of a Miguel Servet type I programme fellowship from the ISCIII, co-funded by the European Social Fund (ESF, "Investing in your future") (CP16/00033). FG is a recipient of a Sara Borrell post-doctoral fellowship from the ISCIII, co-funded by ESF (CD15/00095). SR-M is supported by funds of the RETICS Program (RIER) RD16/0012/0009 (ISCIII, 
co-funded by the European Regional Development Fund, ERDF). VM is supported by funds of a Miguel Servet type I programme (CP16/00033) (ISCIII, cofunded by ERDF).

Disclosure of Interest: None declared

DOI: 10.1136/annrheumdis-2018-eular.5614

\section{SAT0171 REVERSIBLE DECREASES IN ABSOLUTE NEUTROPHIL COUNT (ANC) IN RHEUMATOID ARTHRITIS (RA) PATIENTS (PTS) ON SARILUMAB: COMPARISON OF DOSE DELAY AND DOSE DECREASE VS CONTINUED TREATMENT}

J. R. Curtis ${ }^{1}$, G. St John ${ }^{2}$, M. Panucci ${ }^{2}$, J. A. Maldonado-Cocco ${ }^{3} .{ }^{1}$ Division of Clinical Immunology and Rheumatology, University of Alabama at Birmingham, Birmingham, United States, ${ }^{2}$ Regeneron Pharmaceuticals, Inc, Tarrytown, United States, ${ }^{3}$ Universidad de Buenos Aires, Buenos Aires, Argentina

Background: In randomized studies (RCTs: MOBILITY, TARGET and MON$A R C H$ ), and open-label [OLE] EXTEND, for those patients who experienced decreases in ANC this typically occurred early after initiating sarilumab. For sarilumab patients with decreased ANC in the RCTs and the OLE, we assessed the outcomes associated with either continuing treatment, decreasing the sarilumab dose or delaying the dose.

Objectives: The effects of a dose decrease (200 to $150 \mathrm{mg}$ ), dose delay (>17 days), vs no change in treatment were evaluated in RA patients who experienced decreased ANC while on sarilumab 150 or $200 \mathrm{mg}$ q2w. Outcomes data from patients in MONARCH, MOBILITY and TARGET, and MOBILITY and TARGET patients entering EXTEND were analyzed to compare the three strategies. In MONARCH, patients received sarilumab $200 \mathrm{mg}$ q2w. In MOBILITY and TARGET, patients received sarilumab 150 or $200 \mathrm{mg}$ q2w. In EXTEND, patients were switched to, or initiated on, $200 \mathrm{mg}$ q2w.

Table 1 Outcomes following dose delay, dose decrease, or continued treatment with sarilumab among pts who experienced $\mathrm{ANC}<1000 / \mathrm{mm}^{3}$ at any time

\begin{tabular}{|c|c|c|c|c|c|}
\hline \multicolumn{6}{|c|}{ 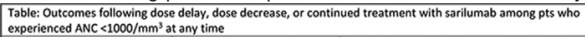 } \\
\hline & \multicolumn{2}{|c|}{ RCTs } & \multicolumn{3}{|c|}{ OLF } \\
\hline Total treated (N) & & \multirow{2}{*}{\multicolumn{3}{|c|}{$147(11)$}} \\
\hline $\begin{array}{l}\text { ANC }<1000 / m^{3} \text { 'at any time } \\
(n,(\%))\end{array}$ & & & & & \\
\hline $\begin{array}{l}\text { Pts who did not continue" (n, } \\
\text { (s)) }\end{array}$ & \multicolumn{2}{|c|}{$\begin{array}{l}24 \\
(23)\end{array}$} & \multicolumn{3}{|c|}{15} \\
\hline \multirow{2}{*}{$\begin{array}{l}\text { Ptst that continued, delayed, } \\
\text { or decreased sarilumab dose } \\
(n,(0))\end{array}$} & \multicolumn{2}{|c|}{$\begin{array}{l}81 \\
(77)\end{array}$} & \multicolumn{3}{|c|}{$\begin{array}{l}132 \\
\text { (90) }\end{array}$} \\
\hline & $\begin{array}{c}\text { Continued } \\
\text { without } \\
\text { change } \\
(\mathrm{n}=38)\end{array}$ & $\begin{array}{c}\text { Dose delay } \\
(n=43)\end{array}$ & $\begin{array}{c}\text { Continued } \\
\text { without } \\
\text { change } \\
(n=31)\end{array}$ & $\begin{array}{c}\text { Dose delay } \\
(n=82)\end{array}$ & $\begin{array}{c}\text { Dose } \\
\text { decrease } \\
(n=62)\end{array}$ \\
\hline 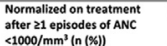 & $\begin{array}{l}25 \\
(66)\end{array}$ & $\begin{array}{l}27 \\
(63)\end{array}$ & $\begin{array}{l}29 \\
(94)\end{array}$ & $\begin{array}{l}66 \\
180)\end{array}$ & $\begin{array}{l}51 \\
(82)\end{array}$ \\
\hline $\begin{array}{l}\text { Median time to } \\
\text { normalization for patients } \\
\text { with 1 a pisisde d days) }\end{array}$ & 9 & 15 & 27 & 17 & 28 \\
\hline 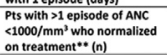 & 6 & 6 & 3 & 33 & 22 \\
\hline $\begin{array}{l}\text { Normalized after treatment } \\
\text { discontiontion }\end{array}$ & 2 & 9 & 1 & 7 & $\begin{array}{c}5 \\
5\end{array}$ \\
\hline 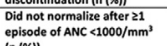 & $\begin{array}{l}\text { (3) } \\
(1)^{\circ} \\
(29)\end{array}$ & $\begin{array}{l}\frac{121}{76} \\
(16)\end{array}$ & $\begin{array}{l}\text { (3) } \\
\text { (3) }\end{array}$ & $\begin{array}{c}91 \\
911)\end{array}$ & $\begin{array}{c}\frac{78)}{6} \\
(10)\end{array}$ \\
\hline $\begin{array}{l}\text { (n)(F)l) } \\
\text { Discontinued treatment due } \\
\text { to abnormal ANC after last } \\
\text { episode (n) }\end{array}$ & 1 & 1 & 1 & 9 & 6 \\
\hline $\begin{array}{l}\text { ANC @ last episode } \\
\left(<2000 / / 1500 /<1000 / \mathrm{mm}^{3} \mid\right.\end{array}$ & $0 / 1 / 0$ & $0 / 1 / 1$ & $1 / 0 / 0$ & $2 / 6 / 1$ & $1 / 4 / 1$ \\
\hline \multicolumn{6}{|c|}{ 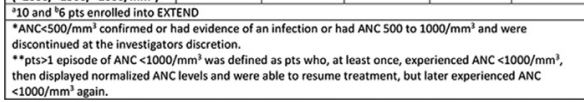 } \\
\hline
\end{tabular}

Methods: In RCTs, patients were required to have baseline neutrophil levels $\geq 2000 / \mathrm{mm}^{3}$. In RCTs and EXTEND, patients who experienced ANC $<500 / \mathrm{mm}^{3}$ (grade 4 [G4] neutropenia) or $\geq 500$ to $<1000 / \mathrm{mm}^{3}$ (grade 3 [G3] neutropenia) and signs of infection were required to permanently discontinue treatment. Patients with G3 neutropenia (no signs of infection) temporarily discontinued treatment (or permanently discontinued at the investigators discretion); patients were retested $\leq 48 \mathrm{hrs}$ after identifying decreased ANC and before the next scheduled dose, and could resume if ANC $\geq 1000 / \mathrm{mm}^{3}$. In RCTs, patients restarted sarilumab at their randomized dose. In OLE, patients restarted sarilumab at $150 \mathrm{mg}$ q2w, as per the protocol, or otherwise were able to restart at $200 \mathrm{mg} \mathrm{q} 2 \mathrm{w}$ at the investigators discretion. In OLE, patients who required a dose decrease to $150 \mathrm{mg}$ q2w sarilumab received the reduced dose for the remainder of the treatment period. ANC normalization was defined as a return to the patient's baseline or within normal ranges. Results: Of the $8-11 \%$ of patients who experienced ANC $<1000 / \mathrm{mm}^{3}$ at any time, $81 / 105$ (RCTs) and 132/147 (OLE) were able to continue or reinitiate sarilumab; the majority of patients who experienced ANC $<1000 / \mathrm{mm}^{3}$ one or more times displayed normalized ANC levels and continued treatment when ANC $\geq 1000 / \mathrm{mm}^{3}$ (25/38 in RCTs; $29 / 31$ in OLE). The majority of patients who dose delayed (27/43 in RCTs; $66 / 82$ in OLE) or dose decreased (51/62, OLE) before ANC normalized resumed treatment.

Conclusions: More than three-quarters of patients who discontinued treatment until ANC normalized were able to reinitiate at their randomized dose (RCT), or at the open-label study dose (200 mg q2w; OLE) or were able to resume at the lowe dose (150 mg q2w; OLE).

Acknowledgements: Study funding and medical writing support (Julie Gray, Adelphi) provided by Sanofi and Regeneron Pharmaceuticals, Inc.

Disclosure of Interest: J. R. Curtis Grant/research support from: Abbvie, Amgen, Bristol-Myers Squibb, Corrona, Janssen, Lilly, Myriad, Pfizer, Roche/ Genentech, UCB, Consultant for: Abbvie, Amgen, Bristol-Myers Squibb, Corrona, Janssen, Lilly, Myriad, Pfizer, Roche/Genentech, UCB, G. St John Shareholde of: Regeneron, Employee of: Regeneron, M. Panucci Shareholder of: Regeneron, Employee of: Boehringer Ingellheim, Regeneron, J. A. Maldonado-Cocco Consultant for: Pfizer, Merck Sharp \& Dohme, Sanofi-Aventis, Novartis, Bristol-Myers Squibb, Roche, Boehringer Ingelheim, Schering-Plough, Abbott, UCB, Eli Lilly Gilead, Speakers bureau: Pfizer, Merck Sharp \& Dohme, Sanofi-Aventis, Novartis, Bristol-Myers Squibb, Roche, Boehringer Ingelheim, Schering-Plough, Abbott UCB, Eli Lilly, Gilead

DOI: 10.1136/annrheumdis-2018-eular.1371

\section{SAT0172 LONG-TERM EFFICACY WITH 5-YEAR-RADIOGRAPHIC RESULTS AND SAFETY OF SARILUMAB IN COMBINATION WITH CSDMARDS IN PATIENTS WITH RHEUMATOID ARTHRITIS}

G. R. Burmester ${ }^{1}$, Y. Lin ${ }^{2}$, G. St John ${ }^{3}$, S. Wang ${ }^{2}$, J. J. Gomez-Reino ${ }^{4}$, J. A. Maldonado-Cocco ${ }^{5}$, J. C. Salazar ${ }^{6}$, D. van der Heijde 7 , M. C. Genovese ${ }^{8}$. ${ }^{1}$ Charité - University Medicine Berlin, Berlin, Germany, ${ }^{2}$ Sanofi Genzyme, Bridgewater, NJ, ${ }^{3}$ Regeneron Pharmaceuticals, Inc, Tarrytown, NY, United States, ${ }^{4}$ IDIS. Complejo Hospitalario Universitario de Santiago, Santiago, Spain, ${ }^{5}$ School of Medicine, Buenos Aires University, Buenos Aires, Argentina, ${ }^{6}$ Clinical Research at Riesgo de Fractura S.A, CAYRE, Bogotá, Colombia, ${ }^{7}$ Leiden University Medical Center, Leiden, Netherlands, ${ }^{8}$ Stanford University Medical Center, Palo Alto, CA, United States

Background: Long-term data are being collected on sarilumab in combination with csDMARDs in patients with RA originally enrolled in six trials (TARGET, NCT01709578; MOBILITY, NCT01061736; NCT01764997; NCT01768572; NCT02057250; NCT01217814) including those who continued into extension trials.

Objectives: To assess efficacy and safety of long-term treatment with sarilumab plus csDMARDs in patients with RA.

Methods: Long-term efficacy and safety data were available in patients enrolled in placebo-controlled trials of sarilumab 150 or $200 \mathrm{mg} \mathrm{sc}$ q2w who continued into the open-label EXTEND trial of sarilumab 200 or $150 \mathrm{mg}$ sc q2w (NCT01146652). Safety data were evaluated in 2887 patients who received $\geq 1$ dose of sarilumab sc in combination with csDMARDs.

Results: Clinical and radiographic efficacy of sarilumab plus csDMARDs was maintained over 5 years' follow-up (table 1; figure 1). Initial treatment with either dose of sarilumab was associated with significantly better radiographic outcome than placebo. Initial treatment with sarilumab $200 \mathrm{mg}$ portended better radiographic outcome than sarilumab $150 \mathrm{mg}$ or placebo. Mean duration of sarilumab treatment in the safety population was 2.6 years ( $\max 6.8$ ), representing 7412 cumulative patient-years of exposure. Incidence rate of adverse events of special interest (AESIs; table 2) was generally stable over $>5$ years' treatment, with no signal for increased rate of any AESI (including serious AEs and serious infection) over time. Incidences of injection site reaction, ANC $<1$ Giga/L, \& elevated ALT declined over time. 